\title{
The influence of ethnicity on breastfeeding rates in Ireland: a cross-sectional study
}

\author{
Emma L Ladewig, ${ }^{1,2}$ Catherine Hayes, ${ }^{1}$ John Browne, ${ }^{3}$ Richard Layte, ${ }^{4}$ \\ Udo Reulbach ${ }^{1,5}$
}

Additional material is

published online only. To view please visit the journal online (http://dx.doi.org/10.1136/jech2013-202735).

1 Department of Public Health and Primary Care, Trinity College Dublin, Dublin, Ireland

${ }^{2}$ Temple Street Children's University Hospital, Dublin, Ireland

${ }^{3}$ Department of Epidemiology and Public Health, University College Cork, Cork, Ireland ${ }^{4}$ The Economic and Social Research Institute, Dublin, Ireland

${ }^{5}$ HRB Centre for Primary Care Research, Royal College of Surgeons in Ireland, Dublin, Ireland

Correspondence to Dr Udo Reulbach, Department of Child and Adolescent Psychiatry, Our Lady's Children's Hospital, Crumlin, Dublin 12, Ireland: reulbacu@tcd.ie

Received 12 April 2013 Revised 11 October 2013 Accepted 19 November 2013

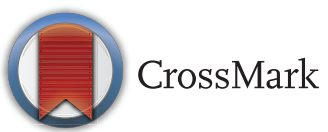

To cite: Ladewig EL, Hayes C, Browne J, et al. J Epidemiol Community Health Published Online First: [please include Day Month Year] doi:10.1136/ jech-2013-202735

\section{ABSTRACT}

Background Historically, breastfeeding rates in Ireland have been low compared with international averages. It has been suggested that maternal ethnicity and citizenship may influence breastfeeding rates, with ethnic minorities thought more likely to breast feed.

Aim The aim of this study is to investigate the association among maternal citizenship, ethnicity, birthplace and breast feeding. It is hypothesised that Irish mothers (identified through Irish citizenship, selfidentified Irish ethnicity or Irish birthplace) are less likely to breast feed than non-lrish mothers.

Methods The study population of Growing Up in Ireland: the National Longitudinal Study of Children was used for this study. Analysis was restricted to 11092 biological mother and infant pairs with a complete breastfeeding history. Logistic regression analysis was used to estimate ORs and $95 \% \mathrm{Cls}$ for breast feeding relative to maternal citizenship and ethnicity, controlling for the confounding effects of other maternal variables. Results Results indicated that $55.9 \%$ (6202 of 11 092) of mothers had initiated breast feeding, with only $7.9 \%$ (874 of 11 092) of mothers currently breast feeding their infant (at 9 months of age). Irish citizens (4693 of 9368 , $50.0 \%$ ) were significantly less likely to have initiated breast feeding compared with non-Irish citizens (1503 of $1695,88.7 \%$ ). Irish born mothers (4179 of 8627 , $48.8 \%$ ) were also significantly less likely to have initiated breast feeding than mothers born elsewhere (2023 of 2462, 82.2\%).

Conclusions Maternal citizenship and ethnicity appear to be the strongest influencing factors on breastfeeding initiation and duration. However, this raises a possibility that the increase in breastfeeding rates seen recently may be the result of increased immigration into Ireland, rather than the success of policy and research efforts.

\section{BACKGROUND}

Nutrition plays a major role in determining health across the lifespan, and nutritional status early in life may impact on future health. Research has found that feeding in infancy is a crucial factor in determining and influencing growth and development. ${ }^{1}{ }^{2}$ Breast feeding has been recommended as the optimal form of nutrition for infants worldwide. WHO recommends exclusive breast feeding for the first 6 months of life, followed by continued breast feeding along with appropriate complementary feeding until at least 2 years of age. ${ }^{3}$

While breast feeding is associated with purported benefits, potential maternal costs also exist. Breast feeding may be associated with increased risk of maternal infection, pain and may negatively impact upon maternal earning potential. ${ }^{4}$ Further, it has been suggested that WHO breastfeeding guidelines are unattainable for many women due to personal and professional restrictions. ${ }^{6}$ While many mothers in other countries struggle to meet recommendations of exclusive breast feeding for 6 months, ${ }^{7}$ a different problem exists in Ireland, with Irish mothers struggling to even initiate breast feeding. ${ }^{8}$

Historically, breastfeeding initiation and maintenance rates in Ireland have been low compared with other European countries. Irish breastfeeding rates saw a steep decline from $64 \%$ of all mothers initiating breast feeding in the 1950 s to $16 \%$ of all mothers in the 1970s. ${ }^{9}$ During the 1980s, a series of studies commissioned by the Health Education Bureau found that $30 \%-35 \%$ of mothers were breast feeding upon leaving hospital in Ireland. ${ }^{10} 11$ While these figures represented a significant increase since the 1970 s, the rates were still low compared with other developed countries.

Since the mid-1990s, government led strategic action plans have been implemented with the aim to increase breastfeeding initiation and duration rates. A pan European growth study in the year 2000 assessed breastfeeding levels across 22 European countries, with breastfeeding levels in Ireland found to be the lowest in Europe. Only a quarter of Irish women surveyed initiated breast feeding, compared with $94 \%$ in Hungary, $94 \%$ in Sweden and 99\% in Greece. ${ }^{8}$ The 2003 wave of data collection of the Survey of Lifestyles, Attitudes and Nutrition in Ireland found that 32\% of all mothers in Ireland initiated breast feeding. ${ }^{12}$ The subsequent 2008 wave of SLAN data collection found that initiation rates had increased to $42 \%,{ }^{13}{ }^{14}$ and a 2010 review found that $44.5 \%$ of mothers in Ireland had initiated breast feeding. These figures suggest that the implementation of breastfeeding policies has been partially successful in increasing breastfeeding levels in Ireland, but there is still much room for improvement.

A number of small, regional studies have investigated factors influencing breastfeeding initiation and duration in Ireland. ${ }^{15-17}$ The strongest and most consistently cited factors are maternal age, maternal smoking and maternal education, which is in line with previous international research. ${ }^{13}{ }^{18}$ However, these factors do not provide an adequate explanation of the low breastfeeding rates in Ireland, as countries with comparable maternal education and age statistics have significantly higher rates of breast feeding.

It has been suggested that citizenship and ethnicity may influence breastfeeding rates, with nonnationals living in Ireland more likely to breast feed than Irish nationals. ${ }^{19}$ A combination of factors 
including economic growth, a property bubble and a more relaxed immigration regime resulted in a sustained period of increased immigration into Ireland between the years 2000 and 2008. It is difficult to determine absolute immigration rates, as clear records do not exist; however, the population census showed an increase in the percentage of non-nationals and a decrease of Irish nationals living in Ireland between 2000 and $2008 .^{20}$

This paper describes the first study to use a nationally representative population based cohort study to examine the influence of citizenship, ethnicity and birthplace on breastfeeding initiation and duration in Ireland.

\section{METHODS}

\section{Study definitions}

The following definitions will be used throughout the paper. Breastfeeding initiation refers to mothers who have ever breast fed their infant. Exclusive breast feeding refers to infants who only receive breast milk without any additional food or drink. Partial breast feeding refers to infants who receive breast milk and additional food or drink. Current breast feeding refers to mothers who were breast feeding their infant at the time of interview (infant 9 months old), and includes exclusive and partial breast feeding. In the above categories, it was not specified if the infant was receiving expressed breast milk.

Irish citizenship refers to mothers who hold Irish citizenship. Irish ethnicity refers to mothers who identify themselves as having an Irish ethnic background. Irish birthplace refers to mothers who were born in Ireland.

\section{Aim}

The aim of this study is to investigate the association among maternal citizenship, ethnicity, birthplace and breast feeding.

\section{Research question}

Are Irish mothers (identified through Irish citizenship, selfidentified Irish ethnicity or Irish birthplace) less likely to breast feed than non-Irish mothers?

\section{Design}

The current study uses an observational cross-sectional design.

\section{Setting}

This study presents findings from the first wave of data collection from Growing Up in Ireland: the National Longitudinal Study of Children (GUI). The research setting for GUI is the Republic of Ireland.

\section{Population}

The sample of 11134 infants and their families was randomly selected from the Child Benefit Register maintained by the Department of Social Protection. A validation exercise completed by the GUI study team identified the Child Benefit Register as an ideal sampling frame for the GUI study. ${ }^{21}$ Overall, 41185 infants born between December 2007 and June 2008 were recorded on the Child Benefit Register. This period of time was selected as the sampling frame for the GUI study, as data collection was to be carried out between September 2008 and April 2009 when the infants were 9 months old. ${ }^{21}$ The sample size was chosen to be representative of all infants and their families in Ireland. A response rate of $65 \%$ of all families approached was achieved. No exclusion criteria were used, as all infants born within the specified time frame who had been registered were eligible for inclusion in the study.
The sample in the current study was restricted to biological mothers with a complete breastfeeding history: thus, 11092 infants and their mothers were included in the current study (99.6\% of the GUI infant cohort sample).

\section{Data collection}

Data were collected from the primary caregiver of the study infant using detailed questionnaires, administered by trained interviewers. Data were collected between September 2008 and April 2009, with the study infant 9 months old at the time of interview. Participating primary caregivers, usually the mother, gave their informed consent to participate in the study. All interviewers were subject to police vetting and the resulting data were anonymised before being placed in a public archive. Interviews were conducted in the family home.

Mothers were asked a number of questions regarding breastfeeding history including initiation, duration and exclusivity. They were also asked questions regarding their citizenship, ethnicity and birthplace. Mothers not born in Ireland were asked how long they had lived in Ireland. Answers were categorised into length of stay categories that were predetermined by the GUI research team based on immigration research. ${ }^{21}$ For further information on these questions, please see online supplementary appendix 1. The full questionnaire used in GUI is available online (http://www.growingup.ie).

Primary and secondary caregivers were asked an open-ended question about occupation in order to provide information about socioeconomic status. A social class classification was then assigned to both caregivers based on their respective occupations. The family's social class was assigned on the basis of the higher of the two. A threefold classification of family social class is used: professional/managerial (class 1), other non-manual/skilled manual (class 2) and semiskilled/unskilled manual (class 3). ${ }^{21}$

Respondents were also asked to provide details regarding total household income, household size and household composition. Using these data, an equivalised household income was calculated and broken down into quintiles. Information about a number of other variables that might be associated with breastfeeding status was also collected. These variables were maternal age, birth weight of baby, family medical card status, current maternal smoking status, household region, highest maternal education attained and smoking hazard in pregnancy.

\section{Weighting and analysis}

The sample was statistically reweighted on the basis of external population estimates to ensure that it was representative of all Irish infants and their families. Statistical reweighting was performed as a means to balance any unevenness present in the recruited sample as compared with the general population of interest. The weighting system used is based on a minimum information loss algorithm which fits population marginals in a regression framework and adjusts the sample estimates to ensure that they produce estimates which match the population parameters. $^{22}$ The GUI researchers used the program GROSS to generate the weights used. Eleven main characteristics of the infant and their family were used in the generation of the weights: family structure, mother's age, mother's principal economic status, father's principal economic status, family's social class, mother's education, household tenure, region, mother's marital status, mother's citizenship and mother's residency status. $^{21}$

In all analyses, the data were statistically reweighted using the weighting scheme described above. 
Cross-tabulations with $\chi^{2}$ tests with $95 \%$ CIs were used to compute univariate analyses to examine the associations between breastfeeding rates and maternal citizenship and ethnicity variables. Additionally, the association between breastfeeding duration and maternal citizenship and ethnicity was assessed with the log-rank (Mantel-Cox) method.

Multivariate modelling was conducted to examine the association between initiation of breast feeding and various measures of maternal citizenship and ethnicity while controlling for the confounding effect of other maternal variables such as socioeconomic status and maternal age. Logistic regression analysis was used to estimate ORs and 95\% CIs for initiation of breast feeding (outcome variable) relative to maternal citizenship and ethnicity, with maternal education, current maternal smoking, household social class, equivalised household income and maternal age (predictor variables) also included in the models. The non-binary predictor variables were recoded as follows for the purposes of multivariate analysis. Maternal education was coded as lower education (lower secondary or less or leaving cert only) and higher education (non-degree, degree/professional qualification, postgraduate). Household social class was coded as lower class (never worked, semiskilled/unskilled manual) and higher class (other non-manual/skilled manual, professional/managerial). Equivalised household income was divided into two categories using a median split. Maternal age was coded into younger mothers (mothers aged 30 years or younger) and older mothers (mothers older than 30 years). These predictors were selected on the basis of existing literature and research as variables which have found to be associated with breast feeding. In each of four models, a different measure of maternal citizenship or ethnicity was included (maternal citizenship, maternal birthplace, maternal ethnicity and length of time the mother has lived in Ireland). The non-binary predictor variables were recoded as follows. Maternal ethnicity was coded into Irish and non-Irish, and length of time living in Ireland was coded into within the last 5 years and more than 5 years.

Proportions and rates are reported with 95\% CIs. All statistical tests were two sided and a significance level of $\alpha=0.05$ was used. The statistical package SPSS (V.18.0) was used for all analyses.

\section{RESULTS}

Overall, 11 092mothers (median age 32.0 years, IQR 28.0-35.0) and their 9-month-old infants were included in the study. In all, $51.3 \%$ (5695 of 11092 ) of the infant sample was boys. Maternal and household characteristics of the sample are detailed in table 1. Additionally, the median equivalised household income was $€ 18774.77$ (IQR $12302.01-27$ 155.17), with the mean equivalised household income $€ 21$ 199.47 (SD 13 405.63).

The breastfeeding initiation rate for all infants was $56.0 \%$ (6202 of 11 092) which decreased to $48.0 \%$ (5326 of 11092 ) when the baby was brought home from hospital. In all, $44.0 \%$ (4859 of 11 092) of mothers reported that they had ever exclusively breast fed their infant. Overall, 8\% (874 of 11 092) of infants were currently being breast fed.

Irish citizens were significantly $(\mathrm{p}<0.001)$ less likely to have initiated breast feeding, or to be currently breast feeding their infant, than non-Irish citizens (figure 1). The estimated mean duration of breast feeding was 47.8 days (IQR 8.0-120.0) for mothers who are Irish citizens and 112.2 days (IQR 30.0-180.0) for those who are not (figure 2). This difference is statistically significant (log-rank (Mantel-Cox); $\chi^{2}=1001.4$; $\mathrm{df}=1 ; \mathrm{p}<0.001)$.

Mothers who identified with an Irish ethnic background were significantly $(p<0.001)$ less likely to have initiated breast
Table 1 Maternal characteristics

\begin{tabular}{|c|c|c|}
\hline & Prevalence (\%) & Absolute frequencies \\
\hline \multicolumn{3}{|l|}{ Maternal citizenship } \\
\hline Irish citizen & 84.7 & $\mathrm{~N}=9388$ \\
\hline Non-Irish citizen & 15.3 & $\mathrm{~N}=1695$ \\
\hline \multicolumn{3}{|l|}{ Maternal birthplace } \\
\hline Born in Ireland & 77.8 & $N=8629$ \\
\hline Born elsewhere & 22.2 & $N=2463$ \\
\hline \multicolumn{3}{|c|}{ Length of time living in Ireland* (years) } \\
\hline$<1$ & 1.0 & $\mathrm{~N}=24$ \\
\hline $1-5$ & 43.5 & $\mathrm{~N}=1069$ \\
\hline $6-10$ & 28.3 & $\mathrm{~N}=696$ \\
\hline $11-20$ & 10.0 & $\mathrm{~N}=246$ \\
\hline$>20$ & 17.1 & $\mathrm{~N}=421$ \\
\hline \multicolumn{3}{|l|}{ Maternal cultural background } \\
\hline Irish & 83.6 & $\mathrm{~N}=9242$ \\
\hline Any other white & 10.9 & $N=1200$ \\
\hline African or any other black & 2.6 & $\mathrm{~N}=293$ \\
\hline Chinese or any other Asian & 2.4 & $\mathrm{~N}=270$ \\
\hline Other (including mixed) & 0.5 & $\mathrm{~N}=53$ \\
\hline \multicolumn{3}{|l|}{ Maternal age (year) } \\
\hline$<19$ & 1.8 & $\mathrm{~N}=205$ \\
\hline $20-25$ & 13.4 & $\mathrm{~N}=1483$ \\
\hline $26-30$ & 23.6 & $\mathrm{~N}=2618$ \\
\hline $31-35$ & 36.4 & $\mathrm{~N}=4037$ \\
\hline $36-39$ & 18.4 & $\mathrm{~N}=2042$ \\
\hline$>40$ & 6.4 & $\mathrm{~N}=707$ \\
\hline \multicolumn{3}{|l|}{ Maternal education } \\
\hline Lower secondary or less & 17.6 & $\mathrm{~N}=1952$ \\
\hline Leaving certificate & 25.3 & $N=2800$ \\
\hline Non-degree & 28.0 & $N=3101$ \\
\hline Professional qualification/degree & 17.5 & $N=1936$ \\
\hline Postgraduate & 11.7 & $\mathrm{~N}=1292$ \\
\hline \multicolumn{3}{|l|}{ Household social class } \\
\hline Professional/managerial & 47.9 & $N=5311$ \\
\hline Other non-manual/skilled manual & 32.8 & $\mathrm{~N}=3633$ \\
\hline Semiskilled/unskilled manual & 9.8 & $\mathrm{~N}=1088$ \\
\hline Never worked & 9.0 & $\mathrm{~N}=1001$ \\
\hline \multicolumn{3}{|l|}{ Current maternal smoking status } \\
\hline Mother is currently smoking & 25.6 & $\mathrm{~N}=2842$ \\
\hline Mother is not currently smoking & 74.4 & $\mathrm{~N}=8248$ \\
\hline
\end{tabular}

*Length of time mother has lived in Ireland, for those not born in Ireland.

feeding or to be currently breast feeding their infant than mothers of other ethnic backgrounds (table 2). Further, mothers who were born in Ireland were significantly $(\mathrm{p}<0.001)$ less likely to have initiated breast feeding or to be currently breast feeding than mothers not born in Ireland (table 2). Of those not born in Ireland, breastfeeding rates decreased, as the length of time lived in Ireland increased $(p<0.001)$, with the highest rates seen in those who had moved to Ireland less than 1 year ago (table 2). The mean age of mothers in each of these groups was 29.7 years for those living here less than 1 year, 28.7 years for 1-5 years, 31.9 years for 6-10 years, 31.4 years for $11-12$ years and 34.6 years for more than 20 years.

Increased maternal age was found to be a significant predictor of breastfeeding initiation and continuation (table 3). Mothers in higher education groups and older mothers were significantly $(p<0.001)$ more likely to have initiated breast feeding, or to be currently breast feeding, their infant than mothers in lower education groups and younger mothers (table 3 ). 


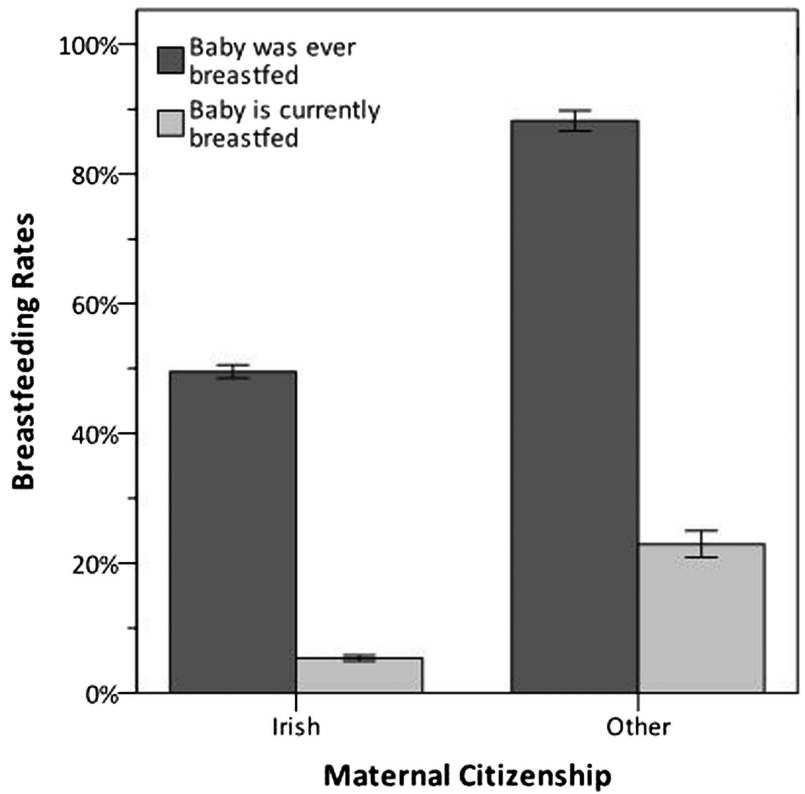

Error bars: $95 \% \mathrm{Cl}$

Figure 1 Breastfeeding rates and maternal citizenship.

In multivariate regression models, maternal citizenship, maternal ethnic background, maternal birthplace and length of time the mother has lived in Ireland were found to be significantly associated with breastfeeding initiation and continuation, with Irish mothers significantly less likely to breast feed than non-Irish mothers $(\mathrm{p}<0.001)$ (table 4$)$. The figures presented in the third row (Maternal citizenship/ethnicity/birthplace) are ORs and 95\% CIs for initiating breast feeding for each of the primary predictor variables (Citizenship, ethnicity, birthplace, length of time living in Ireland) as specified in the second row of the table. For example, in Model 1 (the primary predictor variable included in this model is citizenship), the OR for a non-Irish citizen to have initiated breast feeding versus an Irish

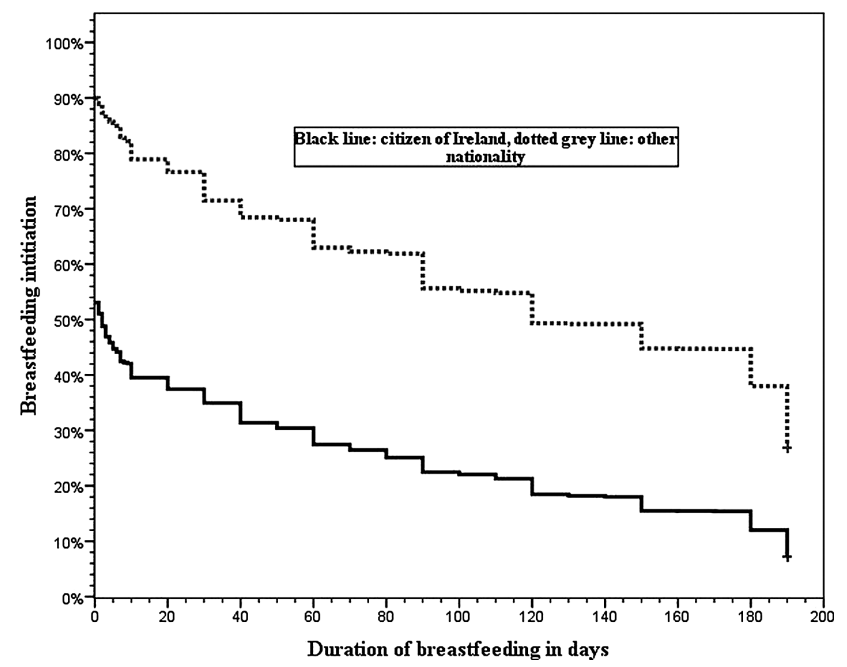

Figure 2 Breastfeeding initiation and duration. Kaplan-Meier plot was created based on the assumption that non-breastfeeding mothers were coded with 0 days duration of breast feeding. For all mothers (including mothers who were currently breast feeding at the time of the study interview), the maximum duration of breast feeding for this plot was limited to 190 days. citizen is 11.3 (95\% CI $9.4 \%$ to $13.8 \%$ ). The remaining figures in the table are ORs and 95\% CIs for initiating breast feeding for each of the other included predictor variables in the four different models (each model including a different measure of maternal citizenship/ethnicity/birthplace). For example in Model 3 (the primary predictor variable included in this model is birthplace), the OR for a higher educated mother to have initiated breast feeding versus a lower educated mother is 2.5 (95\% CI $2.2 \%$ to $2.7 \%)$.

\section{DISCUSSION}

Maternal citizenship and birthplace were among the strongest factors influencing breastfeeding rates. Breastfeeding rates were found to be significantly higher in non-Irish citizens and mothers born elsewhere than in Irish citizens or Irish born mothers. The association between maternal citizenship and ethnicity and breast feeding is further strengthened and clarified in the multivariate modelling presented. Each of the four measures of maternal citizenship and ethnicity (maternal citizenship, maternal birthplace, maternal ethnic background, length of time living in Ireland) were individually found to have the strongest association with breastfeeding initiation when compared with other influencing maternal and socioeconomic variables.

Of mothers not born in Ireland, increased amount of time living in Ireland was found to be significantly associated with lower breastfeeding rates with rates decreasing the longer respondents had lived in Ireland. Maternal age may provide

Table 2 Breastfeeding rates and maternal ethnicity and birthplace

\begin{tabular}{|c|c|c|}
\hline & \multicolumn{2}{|c|}{ Prevalence of breast feeding in each group } \\
\hline & $\begin{array}{l}\text { Initiated breast } \\
\text { feeding* }\end{array}$ & $\begin{array}{l}\text { Currently breast } \\
\text { fedt }\end{array}$ \\
\hline \multicolumn{3}{|l|}{ Maternal birthplace } \\
\hline Born in Ireland & $\begin{array}{l}48.8 \% \\
47.4 \%-49.5 \%\end{array}$ & $\begin{array}{l}4.8 \% \\
4.3 \%-5.2 \%\end{array}$ \\
\hline Born elsewhere & $\begin{array}{l}82.2 \% \\
86.6 \%-83.6 \%\end{array}$ & $\begin{array}{l}19.6 \% \\
18.1 \%-21.2 \%\end{array}$ \\
\hline \multicolumn{3}{|c|}{ Length of time living in Irelandt (years) } \\
\hline$<1$ & $\begin{array}{l}92.0 \% \\
86.4 \%-92.7 \%\end{array}$ & $\begin{array}{l}17.4 \% \\
15.1 \%-23.8 \%\end{array}$ \\
\hline $1-5$ & $\begin{array}{l}89.2 \% \\
88.7 \%-89.7 \%\end{array}$ & $\begin{array}{l}24.1 \% \\
23.4 \%-24.9 \%\end{array}$ \\
\hline $6-10$ & $\begin{array}{l}85.3 \% \\
84.5 \%-86.0 \%\end{array}$ & $\begin{array}{l}19.5 \% \\
18.8 \%-20.4 \%\end{array}$ \\
\hline $11-20$ years & $\begin{array}{l}76.5 \% \\
74.9 \%-77.8 \%\end{array}$ & $\begin{array}{l}18.4 \% \\
17.2 \%-19.9 \%\end{array}$ \\
\hline$>20$ & $\begin{array}{l}62.0 \% \\
60.7 \%-63.2 \%\end{array}$ & $\begin{array}{l}9.4 \% \\
8.8 \%-10.3 \%\end{array}$ \\
\hline \multicolumn{3}{|l|}{ Maternal ethnic background } \\
\hline Irish & $\begin{array}{l}49.5 \% \\
48.5 \%-50.5 \%\end{array}$ & $\begin{array}{l}5.2 \% \\
47.5 \%-56.6 \%\end{array}$ \\
\hline Any other white & $\begin{array}{l}86.5 \% \\
84.4 \%-88.3 \%\end{array}$ & $\begin{array}{l}19.6 \% \\
17.4 \%-21.9 \%\end{array}$ \\
\hline $\begin{array}{l}\text { African or any other } \\
\text { black }\end{array}$ & $\begin{array}{l}92.5 \% \\
88.9 \%-94.9 \%\end{array}$ & $\begin{array}{l}27.4 \% \\
22.5 \%-32.8 \%\end{array}$ \\
\hline $\begin{array}{l}\text { Chinese or any other } \\
\text { Asian }\end{array}$ & $\begin{array}{l}91.5 \% \\
87.5 \%-94.2 \%\end{array}$ & $\begin{array}{l}31.5 \% \\
26.1 \%-37.5 \%\end{array}$ \\
\hline Other (including mixed) & $\begin{array}{l}90.4 \% \\
79.3 \%-95 \%\end{array}$ & $\begin{array}{l}20.8 \% \\
11.8 \%-34.3 \%\end{array}$ \\
\hline
\end{tabular}


Table 3 Breastfeeding rates and maternal age and education

\begin{tabular}{|c|c|c|}
\hline & \multicolumn{2}{|c|}{ Prevalence of breast feeding in each group } \\
\hline & $\begin{array}{l}\text { Initiated breast } \\
\text { feeding* }\end{array}$ & $\begin{array}{l}\text { Currently breast } \\
\text { fedt }\end{array}$ \\
\hline \multicolumn{3}{|l|}{ Maternal age group (years) } \\
\hline$<19$ & $\begin{array}{l}27.8 \% \\
22.1 \%-34.3 \%\end{array}$ & $\begin{array}{l}1.5 \% \\
0.5 \%-4.2 \%\end{array}$ \\
\hline $20-25$ & $\begin{array}{l}43.4 \% \\
40.9 \%-45.9 \%\end{array}$ & $\begin{array}{l}4.1 \% \\
3.2 \%-5.3 \%\end{array}$ \\
\hline $26-30$ & $\begin{array}{l}55.3 \% \\
53.4 \%-57.2 \%\end{array}$ & $\begin{array}{l}8.2 \% \\
7.2 \%-9.3 \%\end{array}$ \\
\hline $31-35$ & $\begin{array}{l}60.1 \% \\
58.6 \%-61.7 \%\end{array}$ & $\begin{array}{l}8.2 \% \\
7.4 \%-9.1 \%\end{array}$ \\
\hline $36-39$ & $\begin{array}{l}58.8 \% \\
56.7 \%-60.9 \%\end{array}$ & $\begin{array}{l}9.5 \% \\
8.3 \%-10.9 \%\end{array}$ \\
\hline$>40$ & $\begin{array}{l}60.6 \% \\
56.9 \%-64.2 \%\end{array}$ & $\begin{array}{l}11.6 \% \\
9.4 \%-14.2 \%\end{array}$ \\
\hline \multicolumn{3}{|l|}{ Maternal education } \\
\hline Lower secondary or less & $\begin{array}{l}29.7 \% \\
27.7 \%-31.7 \%\end{array}$ & $\begin{array}{l}3.2 \% \\
2.5 \%-4.1 \%\end{array}$ \\
\hline Leaving certificate & $\begin{array}{l}46.4 \% \\
44.5 \%-48.2 \%\end{array}$ & $\begin{array}{l}5.3 \% \\
4.5 \%-6.2 \%\end{array}$ \\
\hline Non-degree & $\begin{array}{l}58.4 \% \\
56.6 \%-60.1 \%\end{array}$ & $\begin{array}{l}7.6 \% \\
6.7 \%-8.6 \%\end{array}$ \\
\hline $\begin{array}{l}\text { Professional qualification/ } \\
\text { degree }\end{array}$ & $\begin{array}{l}76.4 \% \\
74.4 \%-78.2 \%\end{array}$ & $\begin{array}{l}12.7 \% \\
11.3 \%-14.3 \%\end{array}$ \\
\hline Postgraduate & $\begin{array}{l}79.8 \% \\
77.5 \%-81.9 \%\end{array}$ & $\begin{array}{l}14.9 \% \\
13.1 \%-16.9 \%\end{array}$ \\
\hline
\end{tabular}

* Mothers who had ever initiated breast feeding.

tMothers who were currently breast feeding (at time of interview).

some explanation of this relationship, as mean age increased in each group the longer they had lived in Ireland.

Breastfeeding rates were significantly lower among women who identified with an Irish ethnic background than any other background, with less than half of these women ever breast feeding. However, breastfeeding rates in all other ethnicity groups were between $80 \%$ and 95\%, with negligible differences between groups. Interestingly, these groups did include ethnic minorities (African/Black, Chinese/Asian, or Other/Mixed) and those who identified with a white ethnic background other than Irish. Across developed countries, women from non-white ethnic groups are more likely to initiate breast feeding and to breast feed for longer than their Caucasian counterparts. ${ }^{23} 24$ While previous evidence has suggested that breastfeeding rates are the highest among ethnic minority groups, this finding does not account for the particularly low rates seen in Ireland. ${ }^{16} 1825$ In the current study, breastfeeding rates among the ethnic minority groups were only fractionally higher than those in the non-Irish white group, indicating that it is Irish ethnicity and not white ethnicity that is associated with lower breastfeeding rates.

Although difficult to quantify absolutely, census figures indicate that rates of immigration into Ireland increased sharply between the years 2000 and $2008 .^{26}$ Interestingly, a steady increase in breast feeding among women in Ireland was also noted during this time, from a $25 \%$ initiation rate recorded in 2000 to the $56 \%$ reported in this study. Data examined in this study were collected between the years 2008 and 2009 when the infant was 9 months old, thus providing a picture of breastfeeding rates in Ireland towards the end of this period of increased immigration. While the noted increase in breastfeeding rates may be attributable to government led policy change and action plans, it is possible that this increase may be a result of the impact of recent immigrants to Ireland, with greater numbers of non-Irish mothers skewing findings.

The current study confirms that while breastfeeding rates in Ireland have increased, they remain below European and international averages. Breastfeeding rates in many other European countries range from $70 \%$ to $99 \%,{ }^{8}$ with only $56 \%$ of Irish mothers in this study initiating breast feeding. A 2010 review comparing breastfeeding rates across the Republic of Ireland and the UK found that $44.5 \%$ of Irish mothers initiated breast feeding compared with 83\% in England, 74\% in Scotland, 71\% in Wales and 64\% in Northern Ireland. ${ }^{27}$

The influence of citizenship and ethnicity on breastfeeding rates in Ireland has been suggested previously; however, earlier studies have used small regional samples, limiting wider application of these results. ${ }^{18} 19$ Previous research both in Ireland and abroad has identified socioeconomic status as the strongest predictor of breastfeeding initiation, with those in lower socioeconomic groups less likely to breast feed. ${ }^{6}{ }^{28}$ While the current findings indicate that variables assumed to be representative of lower socioeconomic class (younger maternal age, lower level of maternal education,

Table 4 OR for initiating breast feeding in mothers of other citizenship, ethnicity and birthplace versus Irish mothers

\begin{tabular}{|c|c|c|c|c|}
\hline & $\begin{array}{l}\text { Model 1* } \\
\text { Citizenship }\end{array}$ & $\begin{array}{l}\text { Model } 2 \dagger \\
\text { Ethnic background }\end{array}$ & $\begin{array}{l}\text { Model } 3 \ddagger \\
\text { Birthplace }\end{array}$ & $\begin{array}{l}\text { Model } 4 \S \\
\text { Length of time living in Ireland }\end{array}$ \\
\hline Maternal Citizenship/ethnicity/birthplace (non-Irish vs Irish) & $\begin{array}{l}11.3 \\
9.4-13.8\end{array}$ & $\begin{array}{l}11.1 \\
9.2-13.4\end{array}$ & $\begin{array}{l}6.2 \\
5.4-7.1\end{array}$ & $\begin{array}{l}3.0 \\
2.3-4.1\end{array}$ \\
\hline Maternal education (higher vs lower) & $\begin{array}{l}2.4 \\
2.2-2.7\end{array}$ & $\begin{array}{l}2.4 \\
2.2-2.6\end{array}$ & $\begin{array}{l}2.5 \\
2.2-2.7\end{array}$ & $\begin{array}{l}2.7 \\
2.1-3.5\end{array}$ \\
\hline Maternal smoking (non-smoker vs smoker) & $\begin{array}{l}1.5 \\
1.4-1.7\end{array}$ & $\begin{array}{l}1.5 \\
1.3-1.7\end{array}$ & $\begin{array}{l}1.5 \\
1.4-1.7\end{array}$ & $\begin{array}{l}2.1 \\
1.6-2.8\end{array}$ \\
\hline Household social class (higher vs lower) & $\begin{array}{l}1.2 \\
1.1-1.4\end{array}$ & $\begin{array}{l}1.2 \\
1.1-1.4\end{array}$ & $\begin{array}{l}1.2 \\
1.1-1.3\end{array}$ & $\begin{array}{l}0.8 \\
0.6-1.1\end{array}$ \\
\hline Household income (higher vs lower) & $\begin{array}{l}1.2 \\
1.1-1.3\end{array}$ & $\begin{array}{l}1.2 \\
1.2-1.5\end{array}$ & $\begin{array}{l}1.2 \\
1.1-1.6\end{array}$ & $\begin{array}{l}1.2 \\
1.1-1.3\end{array}$ \\
\hline Maternal age (older vs younger) & $\begin{array}{l}1.02 \\
1.01-1.03\end{array}$ & $\begin{array}{l}1.02 \\
1.01-1.03\end{array}$ & $\begin{array}{l}1.01 \\
0.99-1.02\end{array}$ & $\begin{array}{l}0.98 \\
0.95-1.00\end{array}$ \\
\hline Nagelkerke $\mathbf{R}^{2}$ & 0.224 & 0.230 & 0.217 & 0.142 \\
\hline
\end{tabular}


maternal smoker, lower household social class and lower household income) were associated with lower breastfeeding rates, in contrast to previous research these variables were not the strongest influencing factors on breastfeeding rates.

Previous research has suggested that availability of supports and structures may strongly influence breastfeeding rates. ${ }^{16} 29$ It has been suggested that availability and length of maternity leave, employer and government support and inhospital education and support are key factors in influencing uptake of breast feeding. ${ }^{30}$ However, a study examining labour market policies in relation to breast feeding does not support this. ${ }^{6}$ Galtry compared practices in Ireland, Sweden and America, and found that rates of maternal employment in Ireland were relatively low, with no suggestion that women returning to work was a factor in low breastfeeding rates. Researchers found that few institutional barriers to breast feeding (in the early months after birth) exist in Ireland, further reinforcing the influence of citizenship and ethnicity. ${ }^{6}$

One limitation of the current study relates to the cross-sectional nature of the data set. As such, we are not able to draw conclusions related to causality, but only infer associations between variables. A further limitation is the lack of available information regarding maternal parity and previous breastfeeding experience. Recent research suggests that a previous positive experience of breast feeding is one of the strongest predictors of breastfeeding uptake. ${ }^{27}$ As such, information regarding previous breastfeeding experience may provide a clearer picture of the current findings. The large sample size used is both a strength and potential methodological weakness. While the large sample size allows for robust and broad comparisons, small differences may potentially be magnified. The authors acknowledge this possibility; however, the findings are significant enough to suggest that a strong relationship would exist even within a smaller sample. A major strength of this study relates to the time frame of data collection. Research has suggested that maternal recall regarding breast feeding and illness is reliable for up to 3 years after. ${ }^{26}$ Data collection in the current study took place when the infant was 9 months old, falling well within this time frame.

Breastfeeding rates in Ireland may be part of a self-perpetuating cycle, as the past two generations have had little exposure to breast feeding, which has resulted in a loss of traditional practice. While the potential benefits and costs of breast feeding can be extensively debated, current national and international guidelines recommend breast feeding as the optimal form of nutrition for infants. Thus, until such a time that sufficient evidence exists to warrant changing these recommendations, extensive support and research should be directed towards increasing breastfeeding rates in Ireland. Policy and institutional efforts to increase breast feeding in this country continue to be developed, including implementation of WHO Baby Friendly Hospital Initiative, and a planned Health Service Executive evaluation of breastfeeding policy. However, greater focus and attention needs to be paid to the influence of Irish citizenship and ethnicity on breastfeeding rates, as identified in this paper.

\section{What is already known on this subject}

- Breast feeding has been well established as the optimal form of nutrition for infants.

- Ireland has one of the lowest rates of breast feeding worldwide, and despite much policy and research effort, remains below European and international averages.

- Ethnicity has been suggested as an influencing factor in breastfeeding rates, though this has not previously been examined in a large scale national study in Ireland.

\section{What this study adds}

- While some increase has been seen, breastfeeding rates in Ireland remain low.

- Maternal ethnicity and citizenship are the strongest factors associated with breastfeeding initiation and duration in Ireland, with Irish mothers less likely to breast feed than non-Irish mothers.

- Mothers from a white non-Irish ethnic background were more likely to breast feed than those from an Irish ethnic background, suggesting that there are factors specific to Irish ethnicity (as opposed to white ethnicity) that influence breastfeeding rates.

Contributors ELL: conception of current study, data analysis and write up. $\mathrm{CH}, \mathrm{JB}$ and RL: critique and contribution to write up. UR: conception of current study, data analysis and contribution to write up.

Funding We wish to acknowledge the funding of the project by the Department of Health and Children, through the Office of the Minister for Children and Youth Affairs, in association with the Department of Social and Family Affairs and the Central Statistics Office. EL was supported by a Research Studentship through the Irish Lung Foundation at the time of this research. UR was supported by the Health Research Board of Ireland through the HRB Centre for Primary Care Research under Grant HRC/2007/1

\section{Competing interests None.}

Ethics approval The first wave of the GUI study was conducted under ethical approval from the research ethics committee of the Health Research Board and conformed to the principles embodied in the Declaration of Helsinki.

Provenance and peer review Not commissioned; externally peer reviewed.

Data sharing statement The data used in this study were collected through Growing Up in Ireland: The National Longitudinal Study of Children. Researchers interested in accessing this data can apply to the Irish Social Science Data Archive (http://www.ucd.ie/issda/).

\section{REFERENCES}

1 Eidelman A, Schanler R. Breastfeeding and the use of human milk. Pediatrics 2012;129:827-41.

2 Horta B, Bahl R, Martines J, et al. Evidence on the long term effects of breastfeeding. WHO, 2007.

3 World Health Organization. Global strategy for infant and young child feeding. World Health Organization, 2003.

4 Mangesi L, Dowswell T. Treatments for breast engorgement during lactation. Cochrane Database Syst Rev 2010;9:1-32.

5 Rippeyoung PLF, Noonan MC. Is Breastfeeding truly cost free? Income consequences of breastfeeding for women. Am Sociol Rev 2012;77:244-67.

6 Galtry J. The impact on breastfeeding of labour market policy and practice in Ireland, Sweden, and the USA. Soc Sci Med 2003;57:167-77.

7 OECD. OECD Family Database. Paris: OECD, 2011.

8 Freeman V, Hof M, Haschke F. Patterns of milk and food intake in infants from birth to age 36 months: the Euro-growth study. J Pediatr Gastroenterol Nutr 2000;31: s76.

9 Kevany J, Taylor M, Kaliszer M, et al. Influences on choice of infant feeding methods. Ir Med J 1975;68:499.

10 McSweeney M, Kevany J, Unit HN, et al. Infant feeding practices in Ireland. Health Education Bureau, 1982.

11 McSweeney M. National survey of infant feeding practices. Dublin: Health Education Bureau, 1986

12 Kelleher C, Nic Gabhainn S, Friel S, et al. The National Health and Lifestyle Surveys: Survey of Lifestyle, Attitudes and Nutrition (SLÁN 2002) and the Irish Health Behaviour in School-Aged Children Survey (HBSC). Centre for Health Promotion Studies, NUI Galway \& The Department of Public Health Medicine and Epidemiology, UCD, 2003.

13 Harrington J, Perry I, Lutomski J, et al. SLÁN 2007: Survey of Lifestyle, Attitudes and Nutrition in Ireland. Dietary Habits of the Irish Population. Psychology Reports. 2008:6.

14 National Committee on Breastfeeding. Breastfeeding in Ireland. A five year strategic action plan. In: Children DoHa, editor. 2005 
15 Tarrant R. An investigation of the diets of infants born in Ireland during the first six months of life. 2008.

16 Begley C, Gallagher L, Clarke M, et al. National infant feeding survey. Dublin: Health Service Executive, 2008.

17 Tarrant RC, Kearney JM. Breastfeeding practices in Ireland: a review. 2008.

18 Tarrant R. An investigation of the diets of infants born in Ireland during the first six months of life. Dublin: Dublin Institute of Technology, 2008.

19 Tarrant RC, Younger KM, Sheridan-Pereira M, et al. Factors associated with weaning practices in term infants: a prospective observational study in Ireland. $\mathrm{Br} J$ Nutr 2010;104:1544-54.

20 Gilmartin M. The changing landscape of Irish migration, 2000-2012. Maynooth, County Kildare: National Institute for Regional and Spatial Analysis, 2012.

21 Greene S, Williams J, Layte R, et al. Growing Up in Ireland. National longitudinal study of children. Background and conceptual framework. Dublin: Stationery Office, 2010.

22 Gomulka J. Grossing up: a note on calculating household weights from family composition totals. University of Cambridge, Department of Economics, Microsimulation Unit Research Note MU/RN/4; 1994.
23 Kelly YJ, Watt RG, Nazroo JY. Racial/ethnic differences in breastfeeding initiation and continuation in the United Kingdom and comparison with findings in the United States. Pediatrics 2006;118:e1428.

24 Heck KE, Braveman P, Cubbin C, et al. Socioeconomic status and breastfeeding initiation among California mothers. Public Health Rep 2006:121:51.

25 Sittlington J, Stewart-Knox B, Wright M, et al. Infant-feeding attitudes of expectant mothers in Northern Ireland. Health Educ Res 2007;22:561.

26 Ruowei L, Scanlon KS, Serdula MK. The validity and reliability of maternal recall of breastfeeding practice. Nutr Rev 2005;63:103-10.

27 NHS. Infant Feeding survey 2010. The Information Centre for Health and Social Care, 2010.

28 Pontin D, Emmett P, Steer C, et al. Patterns of breastfeeding in a UK longitudinal cohort study. Matern Child Nutr 2007;3:2-9.

29 Leahy-Warren P, Mulcahy H, Phelan A. A review of the breastfeeding support services provided by public health nurses in Ireland. Cork: Health Service Executive, 2009.

30 Yngve A, Sjostrom M. Breastfeeding in countries of the European Union and EFTA: current and proposed recommendations, rationale, prevalence, duration and trends. Public Health Nutr 2001;4SPI):631-46. 